This item was submitted to Loughborough's Research Repository by the author.

Items in Figshare are protected by copyright, with all rights reserved, unless otherwise indicated.

\title{
The provision of simple written material does not significantly improve physical activity rates in a population with musculoskeletal problems, a double-blinded randomised controlled trial
}

\section{PLEASE CITE THE PUBLISHED VERSION}

https://doi.org/10.23736/S0022-4707.18.09005-9

\section{PUBLISHER}

(C) Edizioni Minerva Medica

\section{VERSION}

AM (Accepted Manuscript)

\section{PUBLISHER STATEMENT}

This paper was accepted for publication in the journal Journal of Sports Medicine and Physical Fitness and the definitive published version is available at https://doi.org/10.23736/S0022-4707.18.09005-9

\section{LICENCE}

CC BY-NC-ND 4.0

\section{REPOSITORY RECORD}

Wheeler, Patrick. 2019. "The Provision of Simple Written Material Does Not Significantly Improve Physical Activity Rates in a Population with Musculoskeletal Problems, a Double-blinded Randomised Controlled Trial". figshare. https://hdl.handle.net/2134/37293. 


\section{The provision of simple written material does not significantly improve physical activity rates in a population with musculoskeletal problems, a double-blinded randomised controlled trial}

\section{Author}

6 Dr Patrick C. Wheeler ${ }^{1,2,3}$

$7 \quad 1$ - University Hospitals of Leicester NHS Trust, UK

82 -School for Sport, Exercise, \& Health Sciences, Loughborough University, UK

93 - National Centre for Sport \& Exercise Medicine - East Midlands (NCSEM-EM), UK

Institution: All research was carried out at the University Hospitals of Leicester NHS Trust, Leicester, UK

\section{Corresponding author's address}

Dr Patrick C. Wheeler

Department of Sport \& Exercise Medicine

University Hospitals of Leicester NHS Trust

Leicester General Hospital

20 Gwendolen Road

Leicester, LE5 4PW, UK

Publishable email address: p.wheeler@lboro.ac.uk

ORCiD: 0000-0003-2509-9767

Word count (excluding title page, abstract, tables, figs, refs): 3612

The author designed the study, collated the results, analysed the data, and wrote the manuscript.

The research received a favourable ethical response from NRES Committee East Midlands -

Department. 
38 Conflicts of Interest

39 The author declares no conflict of interest

40

$41 \quad$ Funding

42 No external funding was received for this study

43

44 Category

45 Original research - " 3 - the relationship between exercise and health, and the exercise prescription" 46

47 
ABSTRACT

50

The provision of simple written material does not significantly improve physical activity rates in a population with musculoskeletal problems, a double-blinded randomised controlled trial

Background: Physical activity has been shown to have significant health benefits to individuals, being effective in the treatment and prevention of multiple different conditions. However, despite these benefits, rates of physical activity remain low in the western world and less than $40 \%$ of people in the UK meet physical activity recommendations. Musculoskeletal pain can be a barrier to activity, and patients with pain can stop all activity out of fear of harm. This project seeks to see if simple written advice can influence activity rates and behaviours.

62

Methods: A double-blinded randomised controlled trial was conducted to assess any impact of simple written material on physical activity rates in patients attending a single UK National Health Service (NHS) Sports Medicine Department. 546 consecutive patients with a range of musculoskeletal problems were randomised to either an "intervention group" ( $n=235)$ or "control group" ( $n=311)$. Patients in the intervention group received simple written material encouraging of the benefits of physical activity for general aspects of health, including practical steps to increase regular activity in daily life such as commuting, and work.

Results: No significant difference in activity rates were seen between the members of the two groups in any of the outcome measures used. These measures included the short-form/7-day recall version of the International Physical Activity Questionnaire (IPAQ), the General Practitioner Physical Activity Questionnaire (GPPAQ), and the "Vital Signs" questions. There were no differences seen in transport choices. Overall physical activity levels were low among both groups, with only one-third reaching national targets of 150 minutes of moderate-level physical activity per week, and one in five patients undertaking no regular physical activity.

Conclusion: The provision of simple written material does not significantly improve physical activity rates in patients referred to this NHS Sports Medicine Clinic in the UK. Consideration must be given to more tailored and individualised approached to physical activity promotion. 


\section{$84 \quad$ Keywords}

85 - Physical Activity

86 - Exercise

87 - Patient Education Handout

88 - Outcome assessment (health care)

89 
The provision of simple written material does not significantly improve physical activity rates, a double-blinded randomised controlled trial

Introduction

Physical activity has a number of health benefits for individuals, however in western countries activity levels are so low that physical inactivity is reported as the biggest public health problem of the $21^{\text {st }}$ century. ${ }^{1}$ Physical inactivity is the fourth leading cause of preventable death worldwide, accounting for 5 million people dying each year, ${ }^{2,3}$ and in terms of personal health costs, a week of physical inactivity is equivalent to smoking a packet of 20 cigarettes. ${ }^{4}$

Physical fitness has historically been under-recognised as an independent risk factor despite a range of studies over many decades demonstrating the importance of activity for health. ${ }^{5-89}$ Physical activity been shown to reduce the risk of developing high blood pressure, obesity, colon cancer, prostate cancer, diabetes $\&$ heart disease, it helps build and maintain bone health, aids immunity, activity may prevent and treat depression, promotes worker productivity and reduces the incidence of dying prematurely from all causes. ${ }^{10-18}$ Additional benefits are seen in the elderly where regular

110 physical activity has beneficial effects on osteoarthritis, ${ }^{19}$ osteoporosis, ${ }^{20-22}$ fall risk, ${ }^{23,}{ }^{24}$ as well as

111 cognitive impairment risk and progression..$^{25-29}$ Benefits from physical activity have been found from

112 a wide variety of types of activity. The risk of developing coronary heart disease is reduced by

113 regular walking, ${ }^{30,31}$ cycling to work or other forms of active commuting, ${ }^{32,33}$ or four hours (or

$114800 \mathrm{kcals}$ ) of recreational activity per week. ${ }^{34,35}$ The benefits of physical activity are accrued

115 independent of age of onset, with sedentary men who take up activity in their fifties eventually

116 achieving the same benefits as those who have always been active. ${ }^{36}$ 
118 In the UK, the current recommendations from the Home Countries' Chief Medical Officers include all

119 adults aiming to be active daily, attaining a minimum of 150 minutes of moderate-level activity per week (or 75mins vigorous activity), undertaking activity to improve muscle strength twice per week, reducing sitting time, and incorporating balance activities twice per week for older adults who are at risk of falls. ${ }^{37}$ However, despite the benefits of activity and national guidance, levels of physical activity in the UK remain low across all ages; currently only $37 \%$ of men and $24 \%$ of women reach UK guidelines. ${ }^{38-41}$ The UK is one of only seven countries worldwide found to have less than $40 \%$ of the adult population meeting physical activity recommendations. ${ }^{42}$

127 Due to the low general levels of physical activity in the community and the benefits of physical 128 activity across populations, brief physical activity promotion advice should be given to patients who 129 are seen in primary care as a minimum with more detailed rehabilitation offered to those with 130 chronic medical problems. ${ }^{43}$ This should also be the case in secondary care. However research shows 131 that this is rarely addressed in routine clinical practice. ${ }^{44}$ This may be explained at least in part as work has shown that the knowledge of the benefits of physical activity, and the use of activity promotion as opposed to other health promotion approaches, remain low in primary care health professionals. ${ }^{45}$ Accurately measuring physical activity is a challenging area, with advantages and disadvantages of

137 the many different techniques reported in the literature. There are a number of different patient 138 questionnaires in use for assessing levels of physical activity, and this study focuses primarily on two 139 that are in use within the UK, the International Physical Activity Questionnaire (IPAQ) and the

140 General Practice Physical Activity Questionnaire (GPPAQ). With more than 130 peer-reviewed 141 publications, the IPAQ has been well validated for use across a wide range of settings, cultures and 142 languages. ${ }^{46-51}$ It has been developed for the surveillance of populations, is an open access 
143 questionnaire, and is free to use. The GPPAQ was commissioned within the UK by the Department of

144 Health, and developed originally to assist primary health care services to identify patients' levels of

145 physical activity to be able to offer advice and services to reduce their modifiable health risk factors

146 for heart disease. ${ }^{52}$ The IPAQ and GPPAQ can both be used to stratify subjects based on their results,

147 although these groups are not necessarily directly comparable. This stratification is displayed in

148 Table 1.

(INSERT TABLE 1 NEAR HERE)

152 A very simple way of measuring physical activity in the context of a medical consultation was

153 introduced in Kaiser Permanente which listed physical activity as a "vital sign". ${ }^{53}$ This endeavoured to

154 routinely assess physical activity in consultations, in the same way that weight and blood pressure

155 are, by bringing this in as the $5^{\text {th }}$ vital sign. In this process patients are asked two questions:

- "on average, how many days/week do you engage in moderate or greater physical activity (like a brisk walk)?”

- "on those days, how many minutes do you engage in activity at this level?"

These two figures are then multiplied to give an approximate value of the average number of minutes per week of moderate or greater physical activity undertaken. This very rapid tool can identify patients with low levels of physical activity, triggering further analysis and support.

163 Studies in primary care have found that physical activity promotion has a significant increase on 164 physical activity levels at 12 months in adults ${ }^{54}$ although with less of an effect in children. ${ }^{55}$ Tailored 165 interventions can increase walking by up to one hour per week, ${ }^{56}$ and simple "point of decision 166 interventions" can increase activity within various settings. ${ }^{57-61}$ However no published research was 167 found using this strategy to influence active transport to hospital appointments. This study tries to 
encourage the first steps of behaviour change with the provision of simple written material to change a variety of aspects of physical activity patterns.

This randomised controlled trial investigated whether simple written material is able to increase either the regular physical activity, or the use of active transport modalities, of patients attending a hospital musculoskeletal-focussed outpatient clinic. This population may be an ideal target group for exercise promotion as many patients attending the clinic have a range of health problems including osteoarthritis, tendinopathies, chronic pain conditions, and osteoporosis all of which may specifically benefit from activity. ${ }^{20,62-65}$

Material and Methods

Patients referred to a single National Health Service (NHS) Sport \& Exercise Medicine clinic at a large teaching hospital in the UK, were potentially eligible for inclusion to this study. All patients referred during the six-month study period were sent a written letter informing them in general terms of the study investigating physical activity patterns, and that on arrival in the Department for their appointment they would be asked to complete a questionnaire to examine this area. This letter gave the subjects a chance to opt out of the study by telephoning the clinic or advising on arrival.

Subjects were randomised to either the intervention group or the control group on receipt of their referral letter in the clinic, using a random number table drawn up prior to the study commencing.

190 This randomisation process was coordinated by a single member of the clinic administrative staff, 191 managed separately from the clinical staff in the department. The control group had their outpatient 192 appointment booked in the normal manner and aside from the introductory letter received no further contact until they attended for their appointment. The members of the intervention group 
194 also had posted to them written information material to read before their appointment, promoting

195 increased physical activity as part of a daily programme. This information utilised publicly available

196 information about the benefits from the patient.co.uk website. In addition, this included further

197 positive health messages about activity, links to other local resources such as the local council and

198 public health department material on physical activity and resources promoting the use of active

199 transport to attend the hospital appointment such as walking, cycling and local bus routes. There

200 was an average of 6 -weeks between the information being posted to the patients in the intervention

201 group and them attending their first hospital appointment.

202

203 When the subjects attended the clinic for their first appointment, consent was confirmed to

204 continue within the study and patients completed a bespoke study questionnaire, including a range

205 of questions about physical activity. Subjects also had their physical observations (height, weight,

206 blood pressure, etc.) recorded by the clinic nurse. After this was completed the subjects were seen

207 in clinic as per normal practice. Once the questionnaire was completed, members of the control

208 group were also provided with a copy of the same written information that the intervention group

209 had received.

210

211 Inclusion criteria were all patients referred and seen in a single hospital Sport \& Exercise Medicine

212 clinic that were seen from November 2011 to end of May 2012 inclusive. Data was included only for

213 patients that attended their first booked appointment. Subjects failing to attend their initial hospital

214 appointments were recorded and were excluded from this study. Patients had been referred to the

215 hospital clinic for a range of musculoskeletal problems. Common conditions treated include

216 osteoarthritis, various tendinopathies or other soft-tissue musculoskeletal problems including

217 rotator cuff pathology, tennis elbow, plantar fasciitis and Achilles tendinopathy, as well as

218 mechanical low back pain. There are low numbers of patients with inflammatory joint disease or

219 connective tissue disorders also referred. 
Subjects gave explicit consent for inclusion in the study and knew in general terms about the aims of the study, but were not aware of the group allocation until after the questionnaire had been completed, thus ensuring their blinding. The data was analysed by subject number by the Principal Investigator with group un-blinding occurring only after the analysis was complete ensuring investigator blinding.

\section{- Ethical approvals}

This study received a favourable opinion from a local independent Research Ethics Committee,

230 (NRES Committee East Midlands - Northampton, study REC number: 11/EM/0208) and received all necessary site permissions from the host NHS Trust before commencing recruitment.

232

\section{- Data collection form \& statistical analysis}

234 A bespoke data collection form was created for the purposes of this study and was completed by the patient. This questionnaire included the short-form / 7-day recall version of the IPAQ, the GPPAQ, the "Vital Signs" questions, and several specific questions from SF-36, and in addition had a range of bespoke questions written for this study. The questionnaire was informally piloted before use within clinic patients seen in routine practice, with feedback used to shape the final study tool. Whilst the questionnaire was thought by some to be lengthy it was not found to be overly burdensome by the pilot group.

242 Data was obtained from the patient questionnaires and entered into a bespoke Microsoft excel spreadsheet for simple descriptive data, and statistical analysis was conducted with the SPSS analytical package (SPSS Inc, Chicago, IL). Data that had been entered into the spreadsheet was rechecked for accuracy against the paper questionnaire. 
247 Comparisons were made between groups for the range of data collected, including the primary outcome measurements of activity rates, and also the secondary markers. Where appropriate, data was tested using the Shapiro-Wilk test for normality in SPSS. Data that was normally distributed, which included subjects' heights, weights, waist circumference, and diastolic blood pressure, was analysed with two-independent samples T-test to identify the significance of any differences between allocated groups. Ordinal data, and data which was not normally distributed, were analysed with non-parametric testing, predominantly the Mann-Whitney $\mathrm{U}$ test. All analysis was conducted on an intention to treat basis, in that all patients in the intervention group, whether recognising that they were sent the information and whether they read it or not, were compared as a single group with the members of the control group. Statistical significance was set a $p<0.05$

An a priori power calculation was performed with available data using GPower (v3.1.2), which suggested a minimum sample size was 262 , although this was hampered by limited published data on activity rates in this population.

Results

Results were obtained from a total of 546 patients (342 male), over a six-month period from November 2011 to May 2012. During this study period no patients referred during the study period chose to opt out of completing the study questionnaire. $43 \%$ (235/546) (43\%) were randomised to the "intervention group" and were posted the Physical Activity information prior to their appointment, and the remaining 311 to the "control group." Of the Intervention Group, 63\%

$268(147 / 235)$ believed that they had received the information, and of these $95 \%(139 / 147)$ declared 269 that they had read the material, conversely 9\% (27/311) of the Control Group mistakenly believed 270 that they had received the information about physical activity. It is possible that the control group may have mistaken the information about booking their hospital appointment with the Sports 
Medicine Department or answered falsely believing that they had received information and did not

273 want to admit to having not read something they thought they had been posted. This data is

274 displayed in Fig 1 (CONSORT 2010 Flow diagram)

275

276

(INSERT FIG 1 NEAR HERE)

277

278

There were no significant differences between the two groups for the physical and demographic data, except for the patient weight, BMI and waist circumference. Any impact of these differences on activity rates remains unclear. Table 2 displays the physical parameters for the patients in each group. Values shown are mean \pm SD (and range)

282

(INSERT TABLE 2 NEAR HERE)

There were no significant differences in the ethnic origins of the subjects in the intervention and the control groups. Overall the respondents' ethnic origins were reported as 75\% "White", 18\% "Asian / Asian British", 3\% "Black / African / Caribbean / Black British", 2\% "Mixed/multiple ethnicities", and $1 \%$ from "Other ethnic group", these groups reflect the diversity of population of the catchment areas of the clinic.

292 There were found to be no significant differences between the intervention and the control groups

293 in employment status, with a mean household income of $£ 29,766$ and $11.9 \%$ overall reported

294 themselves to have a disability, none of these factors differed significantly between the two groups.

295 There were no significant differences in the location or number of musculoskeletal problems

296 between the intervention and control groups. In addition, two general health questions were asked,

297 including a question about self-reported perceived health rating (question 1 of the SF-36), and the 
298 perception of the subjects' health compared to one year previously (question 2 of the SF-36), and

299 there was no significant difference between the two groups for the answers to either of these

300 questions.

301

\section{- Journeys and transportation types}

303 The intervention group travelled an average of 9.44 miles (range $0.25-195$ ) to their appointment, the

304 control group an average of 10.33 miles (range $0.5-200$ ) and this difference was not statistically

305 significant. The written material that the intervention group received discussed ways of increasing

306 activity through walking or cycling for at least a part of the journey to appointments rather than

307 driving, however there were no significant differences in transport types used to reach the hospital

308 appointment with $91 \%$ attending by car/motorbike (including taxi), $6 \%$ by bus, $2 \%$ walking and $1 \%$

309 cycling.

310

- Measurements of Physical Activity

312 Physical activity was measured in a range of difference methods in this study design.

315 Using the "vital signs" questions as discussed above, there was no significant difference between the

316 intervention and control groups with any of the variables studied. Table 3 displays the mean values

$317 \pm$ standard deviation of the two groups.

(INSERT TABLE 3 NEAR HERE)

322 There were found to be no significant differences between physical activity levels in the intervention and control groups as recorded by the short-form IPAQ. Table 4 displays the proportion of the 
intervention and the control groups in each of the categories of physical activity as determined by the IPAQ. Although in the intervention group there appeared to be fewer patients recorded at "Category 1: Low" and more at "Category 2: Moderate" compared to the control group, the differences were not of statistical significance.

(INSERT TABLE 4 NEAR HERE)

The answers for GPPAQ stratifies subjects into one of four activity groups: "inactive", "moderately inactive", "moderately active" and "active." There were no significant differences in the responses to individual questions within or group allocations based on answers to the GPPAQ for members of the intervention and control groups. Table 5 displays the proportion of subjects in the intervention and control groups in each activity category as assessed by GPPAQ.

(INSERT TABLE 5 NEAR HERE)

341 In case the medical problems that had led to the referral of the subjects to the department had a significant impact on their regular physical activity, subjects were asked to self-report using a categorical system of the minutes of moderate and vigorous activity they undertook in a "typical

344 week" before their current problem, however it is understood that these figures are likely to be 345 affected by recall bias. Subjects were asked about the number of days in a typical week before their 346 problems that they reached either 30 minutes of moderate activity or 20 minutes of vigorous activity

347 (and gave examples of each.) For this question the mean values for the subjects in the intervention 348 group for this question was $3.5 \pm 2.2$ ) and for the control group this was $3.1 \pm 2.2$, this difference was 349 not found to be statistically significant. 


\section{Discussion}

352 This study was not able to show any significant difference in the primary end points studied; that of self-reported physical activity rates through a range of different measures. This study used a number of validated physical activity questionnaires, including the 7-day recall version of the IPAQ, and the GPPAQ. It is possible that the tools used were not sensitive enough to detect small changes, as the study was potentially powered only for a clinically significant change in physical activity for an increase of 30minutes per week and instead the long-form of the IPAQ may have been more sensitive to smaller changes. ${ }^{46}$

This study confirmed a general low level of physical activity across the study population, with only one-third currently meeting a target of 150 minutes moderate activity over a week. In addition, high levels of physical inactivity were recorded, with about one in every five people undertaking no activity in their regular week regardless of which questionnaire was used. These figures are broadly comparable to the results from other published sources, ${ }^{38-42}$ and the real scope of the physical inactivity problem may be higher than is reported here as people are believed to over-report levels of physical activity with written questionnaires..$^{51}$ The results recorded of no activity undertaken for the seven days immediately prior to the appointment were higher than the "typical week" figure of no activity. This difference may represent the effect a current musculoskeletal injury can have on a subject's physical activity rates, a less reliable question format for one of the questions, or an overreporting of physical activity in the "typical week" questions.

372 A weakness of this type of study design is that it relies on patient's being prepared to read the

373 material that they were given and to have sufficient motivation to act upon this, and it was not

374 necessarily clear that all patients received and read the written information that they had been

375 provided with. One way to assess this would be to ask specific questions whose answers would be 
known if the material had been read, although this lay beyond the scope of this study as it was conducted and would have added increased complexity to this study questionnaire which was already relatively lengthy as it asked a range of measures. Due to of this uncertainty the data was analysed on an intention to treat basis, which may had reduced a treatment effect seen from the intervention.

This study did indicate the possibility of an increase in the walking done by members of the intervention group across a range of the questions asked, although these did not reach statistical significance with the size of this study population. The measures most of interest included the frequency and duration of walking done in the last seven days, the number undertaking no walking in the previous week, and the journey chosen to attend the hospital appointment, and some of these measures nearly reached statistical significance, unlike in more intensive intervention studies ${ }^{56}$ However the study may have been underpowered to detect small changes in these areas and further research into this area is suggested, possibly using other patient groups with other medical problems.

There were statistically significant differences noted in in the weight (and hence BMI) of the subjects in the intervention and control groups. It was not clear of the reasons behind this, or any implications that this could have had on the results of the physical activity intervention. An argument could be made that the intervention group, who were slightly leaner, could have been expected to have better physical activity rates than the control group, based on their body composition alone, however this was not shown. It is theoretically possible that the intervention

398 itself which promoted activity and healthy lifestyles could have had an impact on the body 399 composition of the intervention group, although this is an optimistic conclusion to reach given the 400 other limited findings of this study. 
402 One further limitation of this study was the choice of tools that were available to assess physical

403 activity. Due to the study design chosen and the additional funding requirements that would have

404 been needed for accelerometers, the outcome measures of written questionnaires were used. These

405 written questionnaires are valid measures of physical activity, although different numbers of

406 respondents chose to answer different questions, which raises issues of patient compliance with the

407 long survey questionnaire used as a tool in this study. Issues remain over the choices of written

408 questionnaires, with simplicity over length being an important factor. For the sake of brevity the

409 short-form of the IPAQ was used in this study, along with other study tools, however the longer-

410 form of the IPAQ may be able to give more detailed analysis ${ }^{46}$ and may have been more useful in

411 identifying smaller changes to physical activity patterns. These limitations may have been a factor in

412 the limited results that were found. Further research in a similar design which utilises a more robust

413 tool, and one sensitive to small changes in activity rates, is worth considering for population health

414 benefits.

415

416 In conclusion, this study has not shown any significant change in physical activity levels of clinical

417 importance following the use of simple written material, and a more individually tailored response

418 may be required for meaningful population benefit. However, like many habits, physical activity

419 patterns are difficult to change. This study shows that physical activity levels remain low and the

420 majority of subjects in this study do not meet current UK guidance for optimal regular physical

421 activity in their week.

422

423 Acknowledgements

424 The author would like to thank the patients that took part in this study, and the clinic administrative 425 staff for the posting out of the letters and the written material vital for the running of this study.

427 Declaration of interest statement 
428 The author states that there are no declarations of interest regarding this study to disclose.

429 
Table 1: IPAQ and GPPAQ Activity categories

\begin{tabular}{|c|c|}
\hline IPAQ act & GPPAQ activit \\
\hline $\begin{array}{l}\text { - "Low" - This is the lowest level of } \\
\text { physical activity. Those individuals who } \\
\text { not meet criteria for categories } 2 \text { or } 3 \\
\text { - "Moderate" - Any one of the following } \\
3 \text { criteria: } 3 \text { or more days of vigorous } \\
\text { activity of at least } 20 \text { minutes per day } \\
\text { OR } 5 \text { or more days of moderate- } \\
\text { intensity activity or walking of at least } \\
30 \text { minutes per day OR } 5 \text { or more days } \\
\text { of any combination of walking, } \\
\text { moderate-intensity or vigorous } \\
\text { intensity activities achieving a } \\
\text { minimum of at least } 600 \text { MET- } \\
\text { min/week. } \\
\text { "High" - Any one of the following } 2 \\
\text { criteria: Vigorous-intensity activity on } \\
\text { at least } 3 \text { days and accumulating at } \\
\text { least } 1500 \text { MET-minutes/week OR } 7 \text { or } \\
\text { more days of any combination of } \\
\text { walking, moderate-intensity or vigorous } \\
\text { mintensity activities achieving a } \\
\text { minutes/week }\end{array}$ & $\begin{array}{l}\text { - "Inactive" - Sedentary job and no } \\
\text { physical exercise or cycling } \\
\text { "Moderately inactive" - Sedentary job } \\
\text { and some but < 1 hour physical exercise } \\
\text { and / or cycling per week OR Standing } \\
\text { job and no physical exercise or cycling } \\
\text { - "Moderately active" - Sedentary job } \\
\text { and 1-2.9 hours physical exercise and / } \\
\text { or cycling per week OR Standing job } \\
\text { and some but < 1 hour physical exercise } \\
\text { and / or cycling per week OR Physical } \\
\text { job and no physical exercise or cycling } \\
\text { "Active" - Sedentary job and } \geq 3 \text { hours } \\
\text { physical exercise and / or cycling per } \\
\text { week OR Standing job and 1-2.9 hours } \\
\text { physical exercise and / or cycling per } \\
\text { week OR Physical job and some but <1 } \\
\text { hour physical exercise and / or cycling } \\
\text { per week OR Heavy manual job }\end{array}$ \\
\hline
\end{tabular}


436 Table 2: Demographic details of the intervention and control groups

\begin{tabular}{lccc} 
& $\begin{array}{c}\text { Intervention Group } \\
(\mathrm{n}=235)\end{array}$ & $\begin{array}{c}\text { Control Group } \\
(\mathrm{n}=311)\end{array}$ & $p$-value \\
\hline Gender (\% males) & $63 \%$ & $63 \%$ & 0.972 \\
\hline Mean age & $40.9 \pm 16.9$ & $41.0 \pm 15.7$ & 0.874 \\
(range) & $(16-80)$ & $(16-80)$ & \\
\hline Mean height in meters & $1.72 \pm 0.10$ & $1.71 \pm 0.10$ & 0.856 \\
(range) & $(1.50-2.00)$ & $(1.48-2.04)$ & \\
\hline Mean weight in kg & $79.9 \pm 15.7$ & $83.0 \pm 16.3$ & $*$ \\
(range) & $(43.6-121.0)$ & $(45.4-142.9)$ & 0.027 \\
\hline Mean BMI & $27.1 \pm 5.0$ & $28.3 \pm 5.1$ & $*$ \\
(range) & $(18.6-45.2)$ & $(18.2-46.2)$ & 0.006 \\
\hline Mean waist circumference in cm & $91.1 \pm 13.6$ & $93.6 \pm 12.9$ & $*$ \\
(range) & $(56.5-130)$ & $(59-138)$ & 0.028 \\
\hline Mean systolic BP in mmHg & $133.3 \pm 17.5$ & $134.5 \pm 15.4$ & 0.153 \\
(range) & $(101-187)$ & $(100-187)$ & \\
\hline Mean diastolic BP in mmHg & $80.2 \pm 11.6$ & $82.5 \pm 11.3$ & $*$ \\
(range) & $(52-115)$ & $(52-120)$ & 0.022 \\
\hline Mean heart rate in beats per & $73.1 \pm 13.7$ & $74.4 \pm 14.6$ & 0.458 \\
minute (bpm) & $(44-125)$ & $(43-128)$ & \\
(range) & & & \\
\hline
\end{tabular}

$437 *=$ statistically significant difference $(p<0.05)$-found for weight, BMI, waist circumference and 438 diastolic $B P$

439

440 
442 Table 3: Physical activity rates as assessed by "Vital Signs" questions

\begin{tabular}{lcc}
\multicolumn{1}{c}{ "Vital Signs" questions } & $\begin{array}{c}\text { Intervention } \\
\text { Group }\end{array}$ & $\begin{array}{c}\text { Control } \\
\text { Group }\end{array}$ \\
& $(\mathrm{n}=192)$ & $(\mathrm{n}=206)$ \\
\hline Q. On average, how many days per week do you engage & 3.06 & 3.20 \\
in moderate or greater physical activity? & \pm 2.14 & \pm 2.22 \\
\hline Q. On these days, how many minutes do you engage in & 31.71 & 35.15 \\
activity at this level? & \pm 25.9 & \pm 25.8 \\
\hline (calculated) minutes / week of at least moderate activity & 191.59 & 174.58 \\
& \pm 204.2 & \pm 173.3
\end{tabular}

443

444 
446 Table 4: Physical activity rates as assessed by short-form IPAQ

\begin{tabular}{lcc} 
& Intervention & Control \\
IPAQ Categories & $\begin{array}{c}\text { Group } \\
(\mathrm{n}=235)\end{array}$ & $\begin{array}{c}\text { Group } \\
(\mathrm{n}=310)\end{array}$ \\
\hline Category 1: Low & $18 \%$ & $27 \%$ \\
\hline Category 2: Moderate & $33 \%$ & $27 \%$ \\
\hline Category 3: High & $32 \%$ & $32 \%$ \\
\hline Subjects with insufficient information for calculation & $17 \%$ & $14 \%$
\end{tabular}

447

448 
450 Table 5: Physical activity categories as assessed by GPPAQ

\begin{tabular}{|c|c|c|}
\hline GPPAQ Categories & $\begin{array}{c}\text { Intervention } \\
\text { Group } \\
(n=235)\end{array}$ & $\begin{array}{l}\text { Control } \\
\text { Group } \\
(n=311)\end{array}$ \\
\hline Inactive & $22 \%$ & $22 \%$ \\
\hline Moderately inactive & $11 \%$ & $13 \%$ \\
\hline Moderately active & $16 \%$ & $19 \%$ \\
\hline Active & $37 \%$ & $32 \%$ \\
\hline Subjects with insufficient information for calculation & $14 \%$ & $15 \%$ \\
\hline
\end{tabular}

451

452

453

454

455 
458 1. Blair SN. Physical inactivity: the biggest public health problem of the 21 st century. $\mathrm{Br}$ 459 J Sports Med 2009; 43: 1-2.

460 2. World Health Organisation. Global health risks: mortality and burden of disease attributable to selected major health risks. (last accessed 6th October 2012). 2012.

3. Lee IM, Shiroma EJ, Lobelo F, et al. Effect of physical inactivity on major noncommunicable diseases worldwide: an analysis of burden of disease and life expectancy. The Lancet 2012; 380: 219-229. DOI: 10.1016/S0140-6736(12)61031-9.

4654 . Khan KM and Davis JC. A week of physical inactivity has similar health costs to 466 smoking a packet of cigarettes. Br J Sports Med 2010; 44: 395. DOI:

467 10.1136/bjsm.2010.074047.

468 5. Morris JN, Heady JA, Raffle PAB, et al. Coronary Heart Disease and Physical Activity of Work. Lancet 1953; 265: 1053-1057, 1111-1120.

6. Taylor HL, Klepetar E and Keys A. Death rates among physically active and sedentary employees of the railroad industry. Am J Public Health 1962; 52: 1697-1707. 7. Paffenbarger RS, Gima AS and Laughlin ME. Characteristics of longshoremen related to CHD and stroke. AmJ Public Health 1972; 61: 1362-1370.

8. Lee I-M, Blair SN and Jackson AS. Cardiorespiratory fitness, body composition, and all-cause and cardiovascular disease mortality in men. American Journal of Clinical Nutrition 1999; 69: 373-380.

9. Berlin JA and Colditz GA. A meta-analysis of physical activity in the prevention of coronary heart disease. American Journal of Epidemiology 1990; 132: 612-628.

10. United States Department of Health and Human Services Centers for Disease Control and Prevention National Center for Chronic Disease Prevention and Health Promotion. Physical activity and health: A report of the Surgeon General. 1996. Atlanta, GA.

11. HM Government Department of Health. At least five a week: evidence on the impact of physical activity and its relationship to health: report from the Chief Medical Officer. UK: Department of Health, 2004.

12. Booth FW, Gordon SE and Carlson CJ. Waging war on modern chronic diseases: primary prevention through exercise biology. J Appl Physiol 2000; 88: 774-787.

13. Akimoto T, Kumai Y, Akama T, et al. Effects of 12 months of exercise training on salivary secretory IgA levels in elderly subjects. Br J Sports Med 2003; 37: 76-79.

14. U.S. Department of Health and Human Services Office of Disease Prevention and Health Promotion. Healthy Workforce 2010: An Essential Health Promotion Sourcebookfor Employers, Large and Small. 2001. Washington, DC.

15. Brosse AL, Sheets ES, Lett HS, et al. Exercise and the Treatment of Clinical Depression in Adults. Recent Findings and Future Directions. Sports Med 2002; 32: 741-760. 16. Larun L, Nordheim LV, Ekeland E, et al. Exercise in prevention and treatment of anxiety and depression among children and young people. Cochrane Database of Systematic Reviews 2006: Issue 3. Art. No.: CD004691. DOI: 004610.001002/14651858.CD14004691.pub14651852.

17. Mead GE, Morley W, Campbell P, et al. Exercise for depression. Cochrane Database of Systematic Reviews 2008: Issue 4. Art. No.: CD004366. DOI: 004310.001002/14651858.CD14004366.pub14651853.

18. Richman EL, Kenfield SA, Stampfer MJ, et al. Physical Activity after Diagnosis and Risk of Prostate Cancer Progression: Data from the Cancer of the Prostate Strategic Urologic 
503 Research Endeavor. Cancer Research 2011: OnlineFirst May 24, 2011; doi:2010.1158/0008-

504 5472.CAN-2010-3932 DOI: 10.1158/0008-5472.can-10-3932.

505 19. Francen M, McConnell S and Bell M. Exercise for osteoarthritis of the hip or knee.

506 Cochrane Database of Systematic Reviews 2003; (3) CD004286.

507 20. O'Brien M. Osteoporosis and exercise. Br J Sports Med 1996; 30: 191-.

508 21. Rhodes EC, Martin AD, Taunton JE, et al. Effects of one year of resistance training

509 on the relation between muscular strength and bone density in elderly women. Br J Sports

$510 \quad$ Med 2000; 34: 18-22.

511 22. Maimoun L, Simar D, Malatesta D, et al. Response of bone metabolism related

512 hormones to a single session of strenuous exercise in active elderly subjects. Br J Sports Med

513 2005; 39: 497-502.

514 23. Gillespie LD, Gillespie WJ, Robertson MC, et al. Interventions for preventing falls in

515 elderly people. Cochrane Database of Systematic Reviews 2003: Issue 4. Art. No.:

516 CD000340. DOI: 000310.001002/14651858.CD14000340.

517 24. Chang JT, Morton SC, Rubenstein LZ, et al. Interventions for the prevention of falls

518 in older adults: systematic review and meta-analysis of randomised clinical trials. BMJ 2004;

519 328: 680-.

$520 \quad 25 . \quad$ Laurin D, Verreault R and Lindsay J. Physical activity and risk of cognitive

521 impairment and dementia in elderly persons. Arch Neurol 2001; 58: 498-504.

522 26. Abbott RD, White LR and Ross GW. Walking and dementia in physically capable

523 elderly men. JAMA 2004; 292: 1447-1453.

524 27. Weuve J, Kang JH and Manson JE. Physical activity, including walking, and

525 cognitive function in older women. JAMA 2004; 292: 1454-1461.

526 28. Larson EB, Wang L and Bowen JD. Performance-based physical function and future

527 dementia in older people. Archives of Internal Medicine 2006; 166: 115-1120.

528 29. Erickson KI and Kramer AF. Aerobic exercise effects on cognitive and neural

529 plasticity in older adults. Br J Sports Med 2009; 43: 22-24.

53030 . Sesso HD, Paffenbarger RSJ and Lee IM. Physical activity and coronary heart disease

531 in men: The Harvard Alumni Health Study. Circulation 2000; 102: 975-980.

532 31. Manson JE, Greenland $\mathrm{P}$ and La Croix AZ. Walking compared to with vigorous

533 exercise for the prevention of cardiovascular events in women. New England Journal of

534 Medicine 2002; 347: 716-725.

535 32. Andersen LB, Schnor P, Schroll M, et al. All-cause mortality associated with physical

536

537

538

539

540 activity during leisure time, work, sports, and cycling to work. Archives of Internal Medicine 2000; 160: 1621-1628.

33. Vuori I, M., Oja P and Paronen O. Physically active commuting to work - testing its potential for exercise promotion. Med Sci Sports Exerc 1994; 26: 844-850.

34. Wannamathee SG, Shaper AG and Alberti KGMM. Physical activity, metabolic factors and the incidence of coronary heart disease and type 2 diabetes. Archives of Internal Medicine 2000; 160: 2108-2116.

35. Haapanen N, Miilunpalo S, Vuori I, et al. Characteristics of leisure time physical activity associated with decreased risk of premature all-cause and cardiovascular mortality in middle-aged men. American Journal of Epidemiology 1996; 143: 870-880.

546 36. Byberg L, Melhus H, Gedeborg R, et al. Total mortality after changes in leisure time physical activity in 50 year old men: 35 year follow-up of population based cohort. $B M J$ 2009; 338: b688-. DOI: 10.1136/bmj.b688. 
38. HM Government Department of Health. Health Survey for England. Summary of key findings. UK: Department of Health, 2003.

39. USA Centers for Disease Control and Prevention. Youth Risk Behavior Surveillance United States. 1999. MMWR 1999; 49 (SS-5).

40. United States Department of Health and Human Services. Healthy People 2010: With Understanding and Improving Health and Objectives for Improving Health. 2nd ed. 2000. Washington, DC: U.S. Government Printing Office.

41. USA Federal Inter-agency Forum on Aging Related Statistics. Older Americans 2008: Key indicators of well-being. 2008.

42. World Health Organisation. NCD Indicators 2008 data.(accessed 6th October 2012). 2008.

43. Williams NH. Promoting physical activity in primary care. BMJ 2011; 343: $\mathrm{d} 6615$. DOI: $10.1136 /$ bmj.d6615.

44. Shuval K, DiPietro L, Skinner CS, et al. 'Sedentary behaviour counselling': the next step in lifestyle counselling in primary care; pilot findings from the Rapid Assessment Disuse Index (RADI) study. Br J Sports Med 2012. DOI: 10.1136/bjsports-2012-091357.

45. Wheeler PC, Mitchell R, Ghaly M, et al. Primary Care knowledge, and beliefs, about physical activity and health. British Journal of General Practice Open 2017. DOI: 10.3399/bjgpopen17X100809.

46. Craig CL, Marshall AL, Sjöström M, et al. International physical activity questionnaire: 12-country reliability and validity. Med Sci Sports Exerc 2003; 35: 1381-1395. 47. Qu NN and Li KJ. Study on the reliability and validity of international physical activity questionnaire (Chinese Vision, IPAQ). Zhonghua liu xing bing xue za zhi= Zhonghua liuxingbingxue zazhi 2004; 25: 265-268.

48. Vandelanotte C, De Bourdeaudhuij I, Philippaerts R, et al. Reliability and validity of a computerized and Dutch version of the International Physical Activity Questionnaire (IPAQ). Journal of Physical Activity and Health 2005; 2: 63-75.

49. Al-Hazzaa HM. Health-enhancing physical activity among Saudi adults using the International Physical Activity Questionnaire (IPAQ). Public Health Nutrition 2007; 10: 5964. DOI: doi:10.1017/S1368980007184299.

50. Boon RM, Hamlin MJ, Steel GD, et al. Validation of the New Zealand Physical Activity Questionnaire (NZPAQ-LF) and the International Physical Activity Questionnaire (IPAQ-LF) with accelerometry. Br J Sports Med 2010; 44: 741-746. DOI: 10.1136/bjsm.2008.052167.

51. Sebastião E, Gobbi S, Chodzko-Zajko W, et al. The International Physical Activity Questionnaire-long form overestimates self-reported physical activity of Brazilian adults. Public health 2012: doi:10.1016/j.puhe.2012.1007.1004. DOI: 10.1016/j.puhe.2012.07.004. 52. HM Government Department of Health. The General Practice Physical Activity Questionnaire (GPPAQ) - A screening tool to assess adult physical activity levels, within primary care. In: Physical Activity Policy HID, (ed.). UK: Department of Health, 2009. 53. Sallis R. Developing healthcare systems to support exercise: exercise as the fifth vital sign. Br J Sports Med 2011; 45: 473-474. DOI: 10.1136/bjsm.2010.083469.

54. Orrow G, Kinmonth A-L, Sanderson S, et al. Effectiveness of physical activity promotion based in primary care: systematic review and meta-analysis of randomised controlled trials. BMJ 2012; 344: e1389. DOI: 10.1136/bmj.e1389.

55. Metcalf B, Henley W and Wilkin T. Effectiveness of intervention on physical activity of children: systematic review and meta-analysis of controlled trials with objectively measured outcomes (EarlyBird 54). BMJ 2012; 345: e5888. DOI: 10.1136/bmj.e5888. 56. Ogilvie D, Foster CE, Rothnie H, et al. Interventions to promote walking: systematic review. BMJ 2007; 334: 1204-. DOI: 10.1136/bmj.39198.722720.BE. 
602 57. Brownell KD, Stunkard AJ and Albaum JM. Evaluation and modification of exercise 603 patterns in the natural environment. Am J Psychiatry 1980; 137: 1540-1545.

604 58. Kerr J, Eves F and Carroll D. Posters can prompt less active people to use the stairs. $J$ 605 Epidemiol Community Health 2000; 54: 942-943. DOI: 10.1136/jech.54.12.942.

606 59. Andersen RE, Franckowiak SC, Snyder J, et al. Can Inexpensive Signs Encourage the 607 Use of Stairs? Results from a Community Intervention. Ann Intern Med 1998; 129: 363-369.

608 60. Blamey A, Mutrie N and Aitchison T. Health promotion by encouraged use of stairs. 609 BMJ 1995; 311: 289-290.

610 61. Russell WD, Dzewaltowski DA and Ryan GJ. The Effectiveness of a Point-of-

611 decision Prompt in Deterring Sedentary Behavior. Am J Health Promot 1999; 13: 257-259.

612 62. NICE. Osteoarthritis: The care and management of osteoarthritis in adults. National

613 Institute for Health and Clinical Excellence 2008.

614 63. Lawlor DA and Hopker SW. The effectiveness of exercise as an intervention in the 615 management of depression: systematic review and meta-regression analysis of randomised 616 controlled trials. BMJ 2001; 322: 763-. DOI: 10.1136/bmj.320.7231.328.

617 64. Mazzeo RS, Cavanagh P, Evans WJ, et al. American College of Sports Medicine 618 position stand: Exercise and Physical Activity for Older Adults. Med Sci Sports Exerc 1998; 619 30: 992-1008.

620 65. Richards SCM and Scott DL. Prescribed exercise in people with fibromyalgia: 621 parallel group randomised controlled trial. BMJ 2002; 325: 185-. 